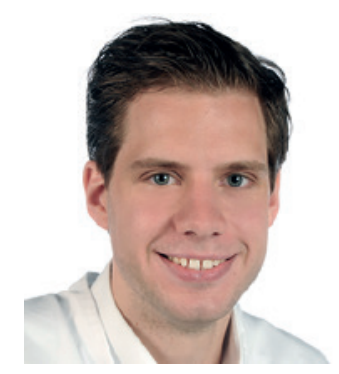

\title{
Seasonal influence on the appearance of central serous retinopathy
}

\author{
Maximilian Treder
}

Klinik für Augenheilkunde, Universitätsklinikum Münster, Münster, Germany

Abstract of Kida T, Kobayashi T, Sato T, et al.: Seasonal variation in Japanese central serous chorioretinopathy. Ophthalmologica 2018;240: 150-156.

\section{Keywords}

Central serous chorioretinopathy · Seasonal variation · Serous retinal detachment . Vascular endothelial growth factor .

Temperature · Choroid · Homeostasis

\section{Abstract \\ Purpose: We investigate seasonal variations found in patients with central serous chorioretinopathy (CSC).}

Methods: We retrospectively investigated 201 CSC patients at the Osaka Medical College Hospital from January 2011 to December 2016 and evaluated their seasonal and monthly distributions.
Results: The study population comprised 149 males and 52 females. There were significant seasonal differences in the distribution of patients, with 62 cases in spring, 37 in summer, 59 in autumn, and 43 in winter, and the monthly prevalence of CSC was high in March ( $n=24)$, April $(n=22)$, and November $(n=23)$. In addition, seasonal variation of serous retinal detachment (SRD) in the macula could be observed in 12 recurrent CSC cases.

Conclusions: The prevalence of CSC development was the highest in spring. In addition, recurrent SRD in the macula showed seasonal variation in some CSC patients. As factors related to CSC, season and temperature might influence the pathophysiology of CSC.

(c) 2018 S. Karger AG, Basel 


\section{Knowledge transfer}

\section{Background}

In central serous retinopathy (CSR), there is a characteristic collection of subretinal serous fluid due to permeability changes in the choroidal vessels as well as a disruption in the barrier function of the retinal pigment epithelium (Fig. 1) [1, 2]. Typical symptoms associated with the morphological changes are worsening vision with perception of a (relative) scotoma in the centre of the visual field, metamorphopsia, or micropsia $[1,2,5]$. With an incidence of $1: 10,000$, CSR is one of the more common macular diseases $[2,5]$. Nonetheless, the exact pathomechanism as well as the influence of various risk factors has not been fully clarified to date. In addition to the known risk factors, such as a typical patient age which peaks around age 45 years, male gender, stress, type A personality and systemic cortisone treatment, there are many other factors whose influence on the development of CSR is the subject of controversial debate in the literature $[1,2,5]$.

\section{Study results}

Against this background, Kida et al. [4] examined the influence of various seasons on the occurrence of CSR. For this purpose, they retrospectively evaluated the medical records of 201 CSR patients between 2011 and 2016 in a monocentre study. First, they documented the season of the initial occurrence of the CSR, and second, they also investigated the appearance of recurrences.

As Figure 2 shows, the authors were able to identify a significant, seasonal frequency of the initial occurrence of CSR in spring and autumn. In 12 patients, they were additionally able to observe seasonal fluctuations in the longitudinal course of the disease.

\section{Conclusion for clinical practice and perspectives for the future}

As the results of Kida et al. show, the season appears to represent an influencing factor for the initial occurrence of CSR and may also influence the appearance of recurrences. As a possible cause of the seasonal differences found, the authors suspect seasonal changes in the choroidal thickness due to corresponding fluctuations in blood pressure and the levels of cortisol, aldosterone, catecholamines and vascular endothelial growth factor (VEGF) [4]. When interpreting the results, it must be borne in mind that a Japanese patient collective was evaluated in the study by Kida et al. However, comparable results could be demonstrated in a US study from the 1980s [3].

Fig. 1. a Optical coherence tomography (OCT) image of a 34-year-old male patient with subretinal fluid in the setting of central serous retinopathy (CSR). $\mathbf{b}$ Later image of the fluorescein angiography of the same patient with characteristic source point.
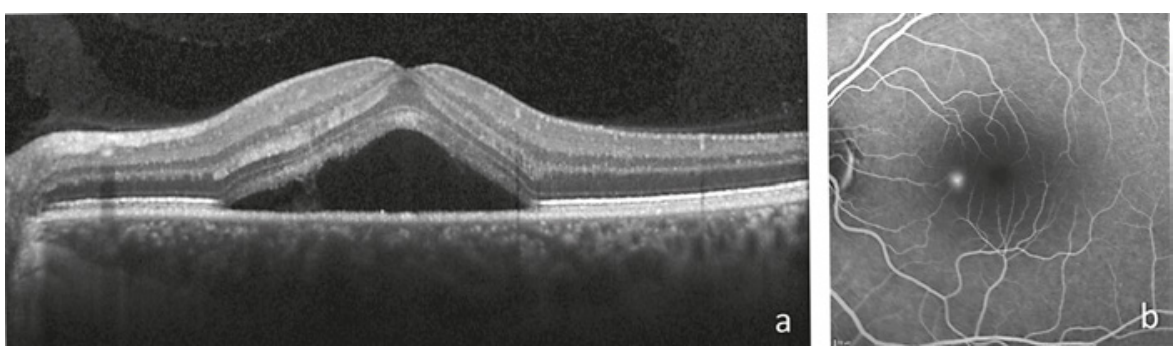

\section{Number of patients}

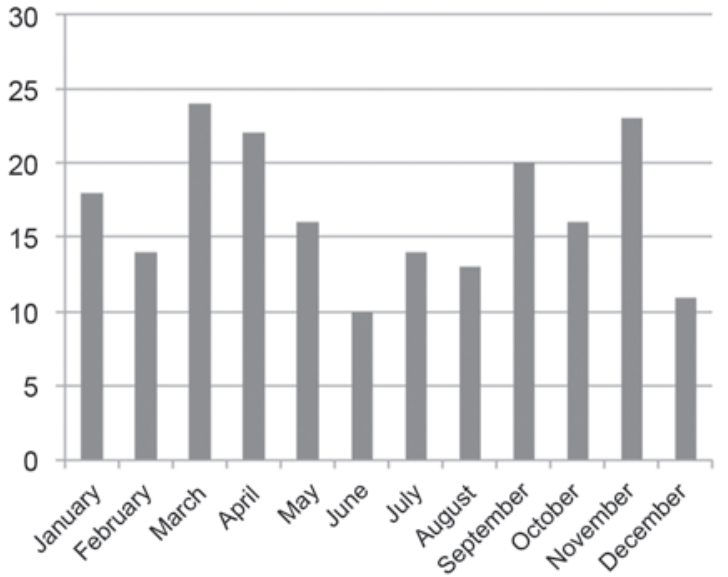

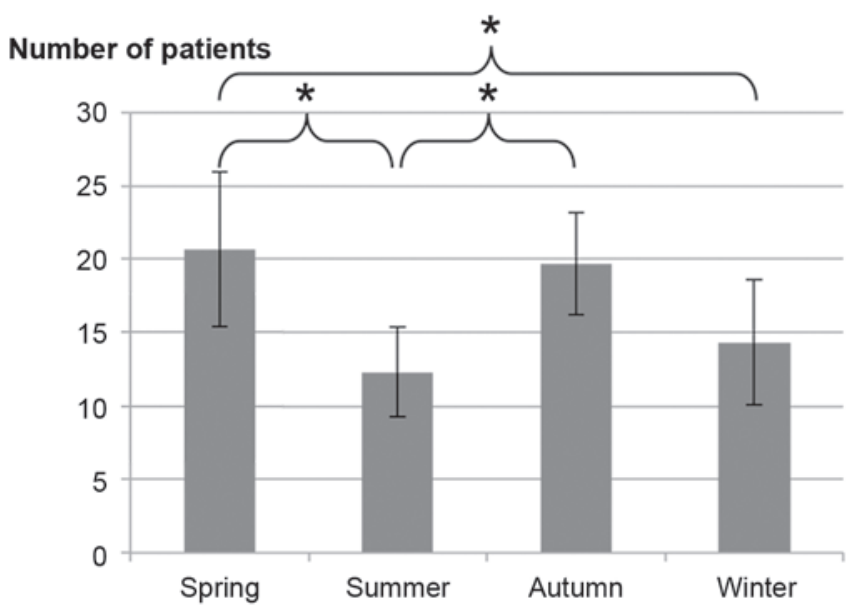

a

Fig. 2. a Monthly and $\mathbf{b}$ seasonal distribution of CSR patients in the study commented on (* significant difference with $p<0.05$ ). Most presentations are in spring and autumn. The month with the most presentations was March (modified according to [4]). 


\section{Disclosure Statement}

I hereby declare that there are no conflicts of interest with regard to this commentary.

\section{Republication}

This article was first published in Karger Kompass Ophthalmol 2019; 5:26-28.

Correspondence: Dr. Maximilian Treder, Klinik für Augenheilkunde, Universitätsklinikum Münster, Albert-Schweitzer-Campus 1, Gebäude D15, 48149 Münster, Germany, maximilian.treder@ukmuenster.de

\section{References}

1 Baraki H, Feltgen N, Roider J, et al.: Chorioretinopathia centralis serosa (CCS). Ophthalmologe 2010;107:479-493.

2 Cakir B, Agostini H, Lange C: Behandlung der Chorioretinopathia centralis serosa mittels Aldosteronantagonisten. Ophthalmologe 2018;DOl:10.1007/ s00347-018-0785-y.

3 Cassel G, Brown G, Annesley W: Central serous chorioretinopathy: a seasonal variation? Br J Ophthalmol 1984;68:724-726.

4 Kida T, Kobayashi T, Sato T, et al.: Seasonal variation in Japanese central serous chorioretinopathy. Ophthalmologica 2018;240:150-156.

5 Liu B, Deng T, Zhang J: Risk factors for central serous chorioretinopathy: a systematic review and meta-analysis. Retina 2016;36:9-19. 